\title{
Perdas Econômicas Decorrentes da Artrite-Encefalite Caprina na Produção de Gordura e Sólidos Totais de Leite ${ }^{1}$
}

Francisco Flávio Dias Carneiro ${ }^{2}$, Roberta Lomonte Lemos de Brito ${ }^{3}$, Vanderlan Warlington Souza dos Santos ${ }^{4}$, Tereza Cristina Lacerda Gomes ${ }^{5}$, Alice Andrioli ${ }^{6}$, Raymundo Rizaldo Pinheiro ${ }^{7}$

Resumo: Objetivou-se determinar as perdas econômicas decorrentes da Artrite-Encefalite Caprina, em parâmetros físico-químicos e de CCS do leite de cabras mestiças, criadas sob as condições ambientais do semiárido Cearense. A avaliação foi conduzida na Fazenda Experimental - Santa Rita, pertencente à Embrapa Caprinos e Ovinos, em Sobral, CE. Foram utilizadas 40 cabras 1/2 Anglo-Nubiana x 1/2 Saanen. A produção leiteira foi verificada através de pesagens diárias durante 210 dias, e neste período, os parâmetros físicoquímicos e de CCS foram mensurados a cada 28 dias. Foram calculadas as receitas com a venda de leite dos diferentes grupos, considerando-se a diferenciação de preço por qualidade. Observou-se que a CAE acarreta perdas econômicas significativas na receita da produção leiteira de cabras mestiças criadas nas condições ambientais do semiárido Cearense. Em virtude da pequena margem de lucro na produção de leite de cabra, estas perdas podem comprometer a rentabilidade da atividade.

Palavras-chave: CAEV, gordura do leite, leite de cabra, retorno econômico, sólidos totais

\section{Economic Losses Resulting from the Caprine Arthritis-Encephalitis in the Production of Fat and Milk Total Solids}

\begin{abstract}
The objective was to determine the economic losses in production of milk's fat and total solids due to the CAE in goat crossbred dairy herd under semiarid environmental conditions of Ceara state. The evaluation was conducted at the Experimental Farm - Santa Rita, which belongs to Embrapa Goats and Sheep, in Sobral, CE. Used 40 1/2 Anglo-Nubian x 1/2 Saanen goats. Milk production was measured by daily weighing during the period of 210 days. Was calculated the revenue from the sale of milk quality for the different groups, considering the price differentiation for quality. It was noted that the CAE causes significant economic losses in revenue from milk production of crossbred goats raised in semiarid environmental conditions of Ceara. As a very small profit margin in the production of goat milk, these losses can compromise the productivity of the activity for the raisers.
\end{abstract}

Key words: CAEV, economic return, fat milk, goat milk, total solids

\footnotetext{
${ }^{1}$ Parte da dissertação de Mestrado do primeiro autor, financiada pela Embrapa Caprinos e Ovinos, Banco do Nordeste do Brasil e Fundação Cearense de Apoio ao Desenvolvimento Científico e Tecnológico - FUNCAP;

${ }^{2}$ Mestrando do Programa de Pós-graduação em Zootecnia - Universidade Estadual Vale do Acaraú - UVA/ Embrapa Caprinos e Ovinos, CE. Bolsista FUNCAP. e-mail: carneiroffd@globo.com

${ }^{3}$ Doutoranda em Medicina Veterinária Preventiva - UNESP/Jaboticabal. e-mail: rolomonte@gmail.com

${ }^{4}$ Graduando em Zootecnia - UVA, Bolsista EMBRAPA. e-mail: vanderlansouza@zootecnista.com.br

${ }^{5}$ Co-orientadora - Professora do Curso de Graduação e Mestrado em Zootecnia da UVA. e-mail: tecris-ce@hotmail.com

${ }^{6}$ Médica Veterinária - Pesquisadora da Embrapa Caprinos e Ovinos, CE; e-mail: alice@cnpc.embrapa.br

${ }^{7}$ Orientador - Médico Veterinário - Pesquisador da Embrapa Caprinos e Ovinos, Professor do Curso de Graduação e Mestrado em Zootecnia da UVA. Estrada Sobral - Groaíras, Zona Rural, Km 4, CEP: 62011-970, caixa postal 145, Sobral, CE . e-mail: rizaldo@cnpc.embrapa.br
} 
Rev. Cient. Prod. Anim., v.13, n.1, p.130-134, 2011

\section{Introdução}

O empreendimento da caprinocultura no Nordeste é afetado pela prática frequente de técnicas inadequadas de manejo alimentar, reprodutivo e sanitário, bem como em virtude da falta de escrituração zootécnica e de diagnóstico tardio de diversas doenças com etiologias distintas, que em sua maioria são controladas de modo impróprio (Pinheiro et al., 2003; Brito, 2009).

A Artrite-Encefalite Caprina (CAE) mostra-se uma enfermidade crônica, incurável, de elevada prevalência em rebanhos leiteiros nacionais e apresenta quatro manifestações clínicas: articular, pulmonar, nervosa e mamária. Sendo esta a que tem impacto econômico direto, devido ao comprometimento da produção leiteira (Greenwood, 1995), redução dos níveis de gordura do leite de cabras soropositivas, redução de 7,2\% do período de lactação, acréscimo na contagem de células somáticas (Greenwood, 1995; Turin et al., 2005; Brito, 2009); diminuição de sólidos totais e predisposição às contaminações secundárias na glândula mamária (Birgel Júnior et al., 2007). Entretanto, não se conhece estudos publicados que tratem da mensuração econômica desses efeitos da CAE.

Diante do exposto, com este estudo, objetivouse determinar as perdas econômicas decorrentes da Artrite-Encefalite Caprina, em parâmetros físicoquímicos e de CCS do leite de cabras mestiças, criadas sob as condições ambientais do semiárido Cearense.

\section{Material e Métodos}

Para avaliação das perdas econômicas foi realizado experimento no período de janeiro a agosto de 2008, na Fazenda Experimental - Santa Rita, pertencente à Embrapa Caprinos e Ovinos, em Sobral, CE, situada a $3^{\circ} 41^{\prime} 32^{\prime}$ 'S e $40^{\circ} 20^{\prime} 53^{\prime \prime} \mathrm{W}, 75 \mathrm{~m}$ de altitude. Foram utilizadas 40 cabras 1/2 Anglo-Nubiana x 1/2 Saanen, sendo 20 soropositivas e 20 soronegativas para CAE, diagnosticadas pelos testes sorológicos de

Imunodifusão em Gel de Agarose - IDGA e "Western Blot" - WB. Antes do estudo, os animais foram submetidos a exame clínico e hemograma completo. As cabras eram de $1^{\mathrm{a}}, 2^{\mathrm{a}}$ e $3^{\mathrm{a}}$ ordens de parto, encontravam-se em média com 26 meses de idade, escore corporal entre 2,0 e 3,0 e peso vivo médio de $37 \mathrm{Kg}$. As matrizes foram mantidas separadas durante todo o experimento em piquetes de pastagem cultivada e irrigada de capim Tanzânia, sendo submetidas estritamente ao mesmo sistema de manejo nutricional, sanitário, reprodutivo e acompanhamento sorológico, por IDGA e WB a cada 60 dias, para detecção de soroconversão no grupo soronegativo.

A ordenha era manual e realizada somente no período da tarde, sendo as cabras soropositivas ordenhadas por último. Amostras de leite individuais foram coletadas a cada 28 dias para a determinação da acidez, densidade, lactose, gordura, proteínas, sólidos totais, extrato seco desengordurado e contagem de células somáticas (CCS). Nas coletas de leite, após a retirada dos três primeiros jatos em caneca de fundo escuro, o pré-dipping era feito com álcool $70 \%$, procedia-se à ordenha normalmente e após a mesma era utilizado o pós-dipping com iodoglicerinado a $0,4 \%$. O leite das cabras era pesado e homogeneizado, sendo em seguida coletado $300 \mathrm{~mL}$ em frascos plásticos, para determinação da acidez e densidade no Laboratório da Usina de Beneficiamento do Leite da Embrapa Caprinos e Ovinos, e em frasco plástico de $50 \mathrm{~mL}$, para a determinação da gordura, proteína, lactose, extrato seco desengordurado, sólidos totais e CCS, no Laboratório de Qualidade do Leite (LQL) da Embrapa Gado de Leite, em Juiz de Fora, MG. O leite foi pesado 
diariamente ao longo de um período de 210 dias e as análises estatísticas dos dados produtivos foram realizadas através dos procedimentos GLM e PRO FREQ do programa estatístico SAS, interpretando-se as médias por análise de variância pelos quadrados mínimos, com níveis de 5\% de significância.

As receitas com a venda de leite dos diferentes grupos foram calculadas, considerando-se a diferenciação de preço por qualidade.

\section{Resultados e Discussão}

Os valores de acidez e densidade não diferiram entre os grupos. As médias dos quadrados mínimos para gordura e sólidos totais foram inferiores para o grupo soropositivo, porém a contagem de células somáticas (CCS) apresentou-se superior. O percentual de proteína, lactose e o extrato seco desengordurado, não diferiram entre os grupos (Tabela 1).

Os preços do leite de cabra adotados foram estabelecidos levando em consideração o programa de pagamento por qualidade - CCA laticínios - Caprilat (Empresa de laticínio do Rio de Janeiro), que considera as características físicoquímicas e demais componentes do leite. Estas se encontravam na mesma categoria de preço, no leite de ambos os rebanhos, exceto pela CCS, que determinou o valor de $\mathrm{R} \$ 1,08$ para o leite com menor CCS e R\$ 1,07 pelo leite com maior CCS. A partir dos referentes valores, calculou-se a receita diária com a venda do leite para os grupos experimentais (Tabela 2).

A debilidade e dificuldade de locomoção dos animais soropositivos pode ter comprometido o pastejo e proporcionado uma redução no consumo de forragem pelas cabras soropositivas afetando a produção de gordura, visto que este parâmetro físicoquímico está intimamente ligado ao consumo de gramíneas. Com a redução da gordura, tem-se também a redução dos sólidos totais e, por conseguinte, comprometimento da renda.

A CCS compromete a qualidade no leite por provocar rancidez (leite cru) e redução na vida de prateleira (leite pasteurizado), bem como por acarretar a redução da firmeza do coágulo, perdas de gordura e caseína afetando o rendimento de queijo (Brito et al., 2001).

$\mathrm{O}$ vírus da CAE debilita os animais, favorecendo problemas pulmonares e de mastite, entre outros e compromete o desempenho produtivo, porém não interfere no consumo de concentrado, sendo assim, o gasto que o produtor tem com a suplementação no grupo soropositivo é o mesmo.

Tabela 1 - Produção de acidez $\left({ }^{\circ} \mathrm{D}\right)$, densidade $(\mathrm{g} / \mathrm{L})$ e médias dos quadrados mínimos de gordura (\%), proteína (\%), lactose (\%), sólidos totais (\%), extrato seco desengordurado (\%) e contagem de células somáticas (x $10^{3}$ células/mL) obtidos no leite de cabras $1 / 2$ Anglo-Nubiana x 1/2 Saanen, soropositivas e soronegativas para 0 vírus da Artrite-Encefalite Caprina

\begin{tabular}{|c|c|c|}
\hline \multirow{2}{*}{ Parâmetros } & \multicolumn{2}{|c|}{ CAEV } \\
\hline & Soronegativas & Soropositivas \\
\hline Acidez $\left({ }^{\circ} \mathrm{D}\right)$ & $14,29 \pm 1,69^{\mathrm{a}}$ & $14,03 \pm 1,97^{\mathrm{a}}$ \\
\hline Densidade $(\mathrm{g} / \mathrm{L})$ & $1031,11 \pm 1,47^{\mathrm{a}}$ & $1031,20 \pm 1,32^{\mathrm{a}}$ \\
\hline Gordura (\%) & $3,76 \pm 0,09^{\mathrm{a}}$ & $3,58 \pm 0,08^{\mathrm{b}}$ \\
\hline Proteína (\%) & $3,20 \pm 0,07^{\mathrm{a}}$ & $3,18 \pm 0,06^{\mathrm{a}}$ \\
\hline Lactose (\%) & $3,83 \pm 0,05^{\mathrm{a}}$ & $3,74 \pm 0,04^{\mathrm{a}}$ \\
\hline Sólidos totais (\%) & $11,55 \pm 0,13^{\mathrm{a}}$ & $11,22 \pm 0,11^{b}$ \\
\hline Extrato seco desengordurado (\%) & $7,79 \pm 0,07^{\mathrm{a}}$ & $7,64 \pm 0,06^{\mathrm{a}}$ \\
\hline Contagem de células somáticas (CCS) (mil cél./ ml) & $2123,42 \pm 262,55^{\mathrm{a}}$ & $2868,52 \pm 221,24^{b}$ \\
\hline
\end{tabular}

Médias seguidas pela mesma letra não diferem estatisticamente pelo teste $\mathrm{t}(\mathrm{P}>0,05)$. 
Tabela 2 - Perdas econômicas da receita diária, por qualidade da produção leiteira, provocada pela ArtriteEncefalite Caprina em rebanho caprino leiteiro no semiárido Cearense

\begin{tabular}{lcc}
\hline \multicolumn{1}{c}{ Produção de leite } & \multicolumn{2}{c}{ CAEV } \\
\cline { 2 - 3 } & Soronegativas & Soropositivas \\
\hline Números de matrizes leiteiras (a) & $20^{\mathrm{a}}$ & $20^{\mathrm{a}}$ \\
Produção média diária animal em Kg de leite (b) & $0,94^{\mathrm{a}}$ & $0,74^{\mathrm{b}}$ \\
Produção total diária do grupo em Kg (a x b) $=(\mathrm{c})$ & $18,8^{\mathrm{a}}$ & $14,8^{\mathrm{b}}$ \\
R\$ em kg (d) & $1,08^{\mathrm{a}}$ & $1,07^{\mathrm{a}}$ \\
\hline Receita ao dia com a venda de leite (c x d) & $20,30^{\mathrm{a}}$ & $15,84^{\mathrm{b}}$ \\
\hline
\end{tabular}

Valores seguidos pela mesma letra na linha não diferem estatisticamente pelo teste $\mathrm{t}(\mathrm{P}>0,05)$.

Ao avaliar o período de lactação de 210 dias observou-se que a produção do grupo soropositivo representou uma receita estatisticamente inferior $(\mathrm{p}<0,05)$ à do grupo soronegativo que equivaleu a $\mathrm{R} \$ 938,28$, representando uma perda de $\mathrm{R} \$ 46,91$ por animal/lactação (Figura 1).

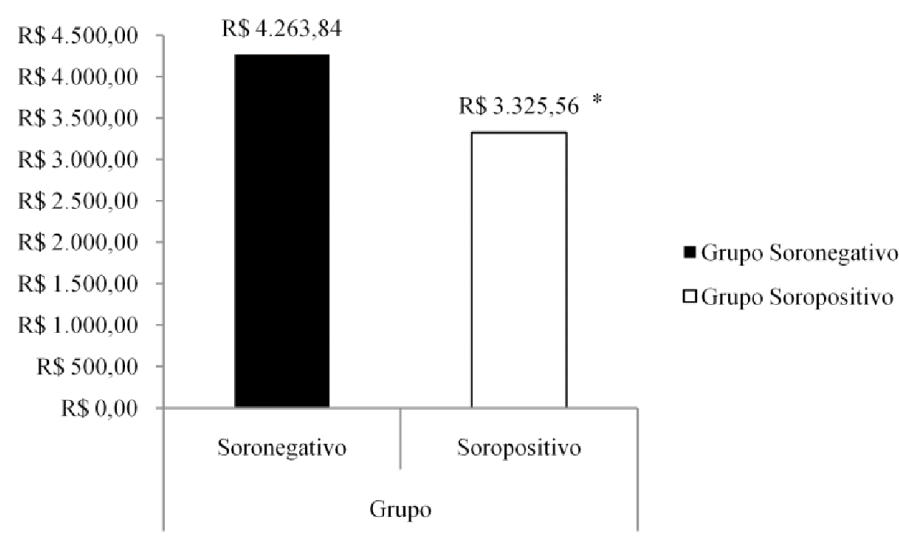

Figura 1 - Valores da produção Láctea, de 210 dias, para venda do leite por qualidade, de caprinos soropositivos e soronegativos para a Artrite-Encefalite Caprina $(* p<0,05)$

Os custos de produção de leite de cabra no Brasil diferem muito entre as unidades produtoras e oscilam entre R \$ 0,72 e R \$ 1,34 segundo a literatura, entretanto a margem de lucro sempre é muito baixa. A perda econômica equivalente a $\mathrm{R}$ \$ 938,28 em uma lactação de 210 dias, em um rebanho de somente 20 matrizes em produção, pode tornar a exploração inviável, sobretudo para os pequenos e médios produtores.

$\mathrm{O}$ vírus compromete a qualidade do leite e, por conseguinte a rentabilidade da atividade. Desta forma, pesquisas em diferentes regiões com animais puros devem ser realizadas com o objetivo de correlacionar os dados obtidos neste estudo.

\section{Conclusões}

As perdas econômicas na receita da produção leiteira de cabras mestiças criadas nas condições ambientais do semiárido Cearense, decorrentes da CAE, comprometem a receita do produtor com maior representatividade quando se considera a diferenciação de preço do leite por qualidade, embora os programas de qualidade não pratiquem ainda valores significativos para a diferenciação (apenas $\mathrm{R} \$ 0,01)$.

\section{Agradecimentos}

À Embrapa Caprinos e Ovinos e Universidade Estadual Vale do Acaraú, por terem fornecido as condições necessárias para realização do estudo, além do auxílio financeiro. Ao Banco do Nordeste do Brasil, Governo do Estado do Ceará e Fundação Cearense de Apoio ao Desenvolvimento Científico e Tecnológico pelo auxílio financeiro.

\section{Literatura Citada}

BIRGEL JUNIOR, E.H.; CESTARI, V.; SAMPAIO, R.M.; LARA, M.C.C.S.H.; BIRGEL, D.B.; RAIMONDO, R.F.S.; BRANDESPIN, F.B.; BIRGEL, E. H. Influência da infecção pelo vírus da artrite encefalite caprina nas características físicoquímicas e celulares do leite de caprinos. Arquivos do Instituto Biológico. v. 74, p.199-206, 2007. 
BRITO, J.R.F.; PINTO, S.M.; BRITO, M.A.V.P.; of dairy goats in NewSouth Wales, Australia. SOUZA, G.N.; ZENI, A. Análise de perigos e pontos Preventive Veterinary Medicine, v. 1-2, n. 22, p. críticos de controle visando a qualidade do leite. In: 71-87, 1995.

MARTINS, C.E. et al. Sustentabilidade da produção

de leite no leste mineiro. 1.ed. Juiz de Fora: Embrapa PINHEIRO, R. R.; CHAGAS, A. C. S.; ANDRIOLI, Gado de Leite, 2001, p.181-195.

A.; ALVES, F. S. F. Viroses de pequenos ruminantes. Sobral, CE: Embrapa Caprinos, 2003. 30 p. (Série BRITO, R. L. L. Implicações da Artrite-Encefalite Documentos, 46).

Caprina na reprodução, produção e na qualidade de leite de cabras. 2009. 109 f. Dissertação (Mestrado em Zootecnia) - Universidade Estadual Vale do Acaraú, Sobral, 2009.

TURIN, L.; PISONI, G.; GIANNINO, M. L.; ANTONINI, M; ROSATI, S.; RUFFO, G.; MORONI, P. Correlation between milk parameters in CAEV seropositive and negative primiparous goats during an

GREENWOOD, P. L. Effects of caprine arthritiseradication program in Italian farm. Small Ruminant encephalitis virus on productivity and health Research, v. 57, p. 73-79, 2005. 